Article

\title{
Cocktail Strategy Based on NK Cell-Derived Exosomes and Their Biomimetic Nanoparticles for Dual Tumor Therapy
}

\author{
Guosheng Wang ${ }^{\dagger}$, Weilei $\mathrm{Hu}^{\dagger}{ }^{\dagger}$, Haiqiong Chen, Xin Shou, Tingting Ye and Yibing $\mathrm{Xu}^{*}$ \\ Institute of Translational Medicine, Zhejiang University School of Medicine, Hangzhou 310029, China; \\ 21518460@zju.edu.cn (G.W.); weileihu@zju.edu.cn (W.H.); 182594@zju.edu.cn (H.C.); shouxin@zju.edu.cn (X.S.); \\ tingtingye@zju.edu.cn (T.Y.) \\ * Correspondence: yibingxu@zju.edu.cn \\ + These authors contributed equally to this work.
}

Received: 19 September 2019; Accepted: 9 October 2019; Published: 14 October 2019

\begin{abstract}
Successful cancer therapy requires drugs being precisely delivered to tumors. Nanosized drugs have attracted considerable recent attention, but their toxicity and high immunogenicity are important obstacles hampering their clinical translation. Here we report a novel "cocktail therapy" strategy based on excess natural killer cell-derived exosomes (NKEXOs) in combination with their biomimetic core-shell nanoparticles (NNs) for tumor-targeted therapy. The NNs were self- assembled with a dendrimer core loading therapeutic miRNA and a hydrophilic NKEXOs shell. Their successful fabrication was confirmed by transmission electron microscopy (TEM) and confocal laser scanning microscopy (CLSM). The resulting NN/NKEXO cocktail showed highly efficient targeting and therapeutic miRNA delivery to neuroblastoma cells in vivo, as demonstrated by two-photon excited scanning fluorescence imaging (TPEFI) and with an IVIS Spectrum in vivo imaging system (IVIS), leading to dual inhibition of tumor growth. With unique biocompatibility, we propose this NN/NKEXO cocktail as a new avenue for tumor therapy, with potential prospects for clinical applications.
\end{abstract}

Keywords: antitumor strategy; biomimetic core-shell nanoparticles; NK cell-derived exosomes; drug delivery system

\section{Introduction}

Targeted drug delivery systems for cancer therapy have attracted considerable recent attention owing to their high delivery efficiency along with minimal side effects [1-3]. Polymers are of great significance in targeted drug delivery as nanocarriers for biomacromolecular agents. Among them, polyamidoamine (PAMAM), the first reported and commercialized dendrimers, are hyperbranched polymers with a globular structure, which efficiently transfer nucleic acids (DNA, siRNA, miRNA, etc.) to various cell types and are safer than other cationic polymers [4-6]. PAMAM dendrimers have a distinctive structural feature with positively charged amino groups present at internal cavities, which can interact with negatively charged nucleic acids to form dendriplexes [7,8]. In order to improve their biocompatibility and targeting ability, many strategies have been taken to modify the PAMAM surface, including peptide conjugation, carbohydrate conjugation, acetylation and PEGylation [9].

More recently, biomembrane camouflage strategies have been investigated in cancer therapy. This strategy refers to nanocarriers coated with natural biomembrane components, making them highly versatile in cargo encapsulation and surface functionalization. Many types of membranes have been used to fabricate membrane-camouflaged nanoparticles, including membranes from red 
blood cells, platelets, white blood cells, cancer cells and bacteria [10-15]. Meanwhile, incorporation of membrane proteins within the bilayer of biomimetic nanovesicles using a microfluidic-based platform offers a one-step solution to endow nanoparticles with multiple biological feature such as evading the mononuclear phagocytic system, crossing the biological barriers or targeting inflamed tissues [16-18]. However, without exception, fabrication of core-shell nanoparticles has required extraction of plasma membrane materials by cell lysis and membrane purification, a process that greatly increases the risk of contamination and destruction of functional surface proteins. Therefore, it is of paramount importance for their clinical application to obtain functional off-the-shelf and highly biocompatible materials and establish an efficient and handy synthetic process [19].

Natural killer (NK) cells, known to play a critical role in tumor immunology $[20,21]$ secret exosomes expressing killer proteins, including FASL and perforin, cytotoxic to multiple tumors [22-25]. Previous studies have also demonstrated that natural killer cell-derived exosomes (NKEXOs) have tumor-specific accumulation with no cytotoxic activity against normal tissues [22,23]. Meanwhile, acidic tumor microenvironment facilitates the accumulation of this nanoparticles [26]. Hence, NKEXOs can perform a dual function: They can facilitate tumor targeting and act as direct antitumor agent. More importantly, NK cell-based therapies can act as a renewable product in an allogeneic setting and be given to patients without causing graft-versus-host disease [27]. For these advantages, we ask whether intact NKEXOs could be used directly as camouflage material to greatly simplify synthetic steps and avoid contamination of immunogenic substances due to the destruction progress of membrane extraction.

\section{Results}

\subsection{Characterization and Function of Isolated NKEXOs}

To prepare the nanoparticle (NN)/NKEXO cocktail, we expanded the NK cells to a $94 \%$ purity level by co-culturing peripheral blood mononuclear cells with artificial antigen-presenting cells (aAPC) as previously reported (Figure 1a) $[25,28]$. Then, NKEXOs were isolated and purified from the culture supernatants of NK cells by differential centrifugation [29]. Their size was further measured by dynamic light scattering, showing a mean particle diameter of $100 \mathrm{~nm}$ (Figure 1b). In the purified extracts, typical exosome structures were observed by transmission electron microscopy TEM (Figure 1c). Western blot (WB) analysis indicated that NKEXOs contain typical exosomal proteins (Alix, TSG101 and CD63), together with the absence of cytochrome C (Figure 1d). These data are consistent with those previously reported for typical exosomes [30]. To verify their cytotoxicity towards tumor cells, MDA-MB-231-luc and CHLA-255-luc cells were incubated with NKEXOs for $24 \mathrm{~h}$. As reported previously [22-25], cell viability decreased in both tumor cell lines in a dose-dependent manner (Figure 1e). Internalization of PKH26-labeled NKEXOs into tumor cells was also observed with confocal laser scanning microscopy (CLSM) with a rotating 3D rendering of z-stack images (Figure S1; Video S1). 
a

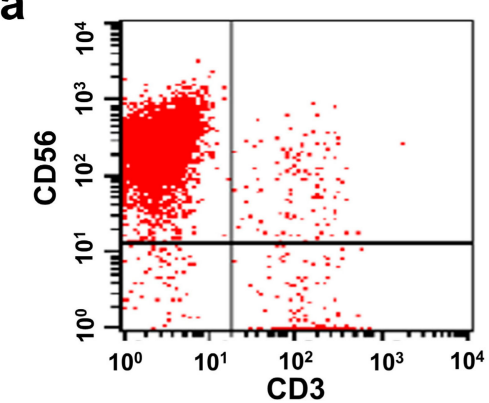

C

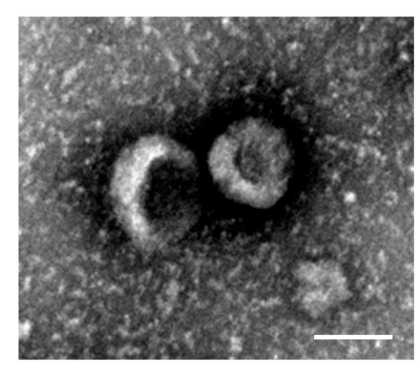

b

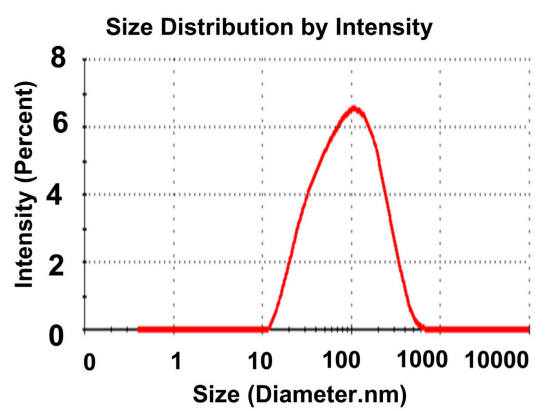

d

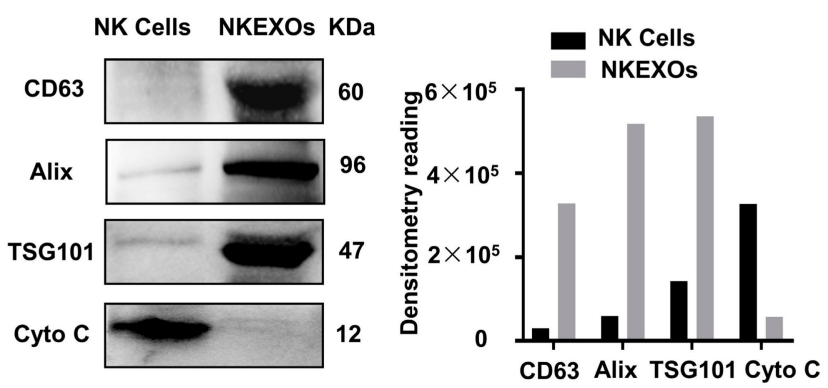

e
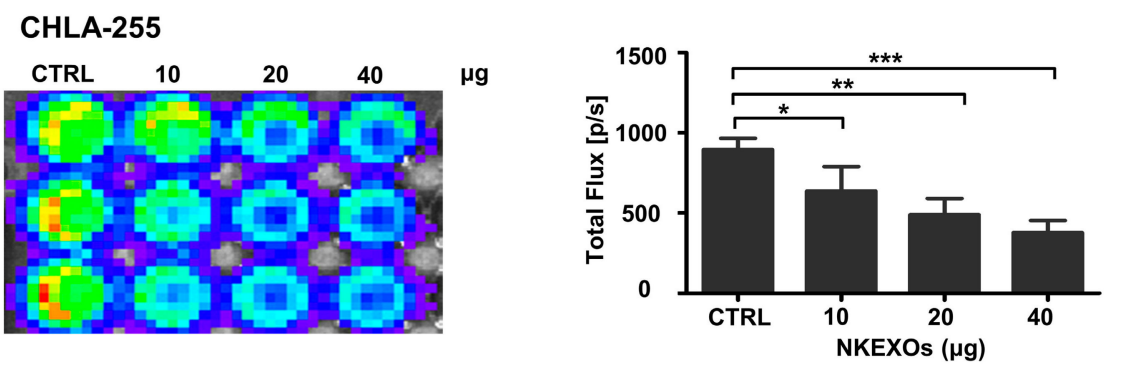

MDA-MB-231
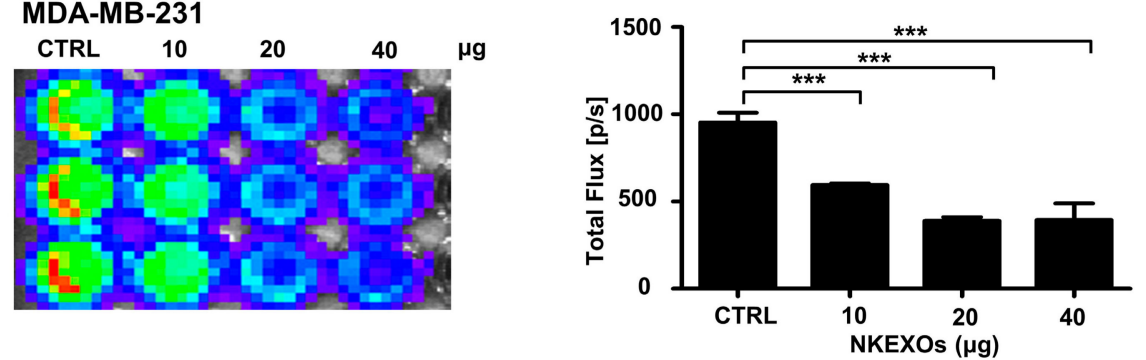

Figure 1. Characterization and function of isolated NKEXOs. (a) Flow cytometric analysis of NK cells (CD3- and CD56+) grown for a total of 21 days. (b) Size distributions of NKEXO measured by dynamic light scattering show peak diameters at $100 \mathrm{~nm}$. (c) The morphology of exosomes was analyzed by transmission electron microscopy. (d) Western blot analysis of CD63, ALIX, TSG101 and cytochrome c (Cyto C) expression level in NK cells and NKEXOs. (e) MDA-MB-231luc and CHLA-255luc cell lines $\left(10^{4}\right.$ cells per well) were incubated with control medium and different amounts of NKEXOs (10, 20 and $40 \mu \mathrm{g}$ ) for $24 \mathrm{~h}$. Cell viability was assessed by bioluminescence imaging. Each bar represents the mean \pm SD of three replicates. ${ }^{*} p<0.05 ;{ }^{* *} p<0.01$ and ${ }^{* * *} p<0.001$.

\subsection{Fabrication and Characterization of the NN/NKEXO Cocktail}

PAMAM dendrimer have been used previously for nucleic acid delivery [4-6]. Using the intrinsic hydrophobicity of the lipid bilayers in the exosome, tyrosine was linked to the dendrimers to promote the binding process [31]. Meanwhile, the phenyl groups of the tyrosine are able to disrupt the endosomal membrane, facilitating release of the therapeutic miRNA [32,33]. The NN/NKEXO cocktail was then prepared by simple incubation of the purified NKEXOs with tyrosine-coupled dendrimers 
preloaded with let-7a mimics (Figure 2a). The resulting NNs were further characterized by TEM, displaying a core-shell structure indicating the presence of the dendrimers in the core and NKEXOs in the shell (Figure $2 b$ ). More importantly, the precipitated NNs contained typical intracellular proteins including TSG101 and Alix, indicating the shell was made of intact exosomes (Figure 2c). Furthermore, the successful coating of the NKEXOs was confirmed by colocalization of the PKH26 (red)-labeled NKEXOs and Fluorescein phosphoramidites FAM (green)-labeled dendrimers (Figure 2d).

In order for the dendrimer core to be fully encapsulated, it is necessary to ensure that the exosomes are always in an excessive state. As an easy and reliable quality control, we used a high-content screening (HCS) system (Operetta, PerkinElmer, Massachusetts, USA) combined with fluorescent staining to determine the parameters for the cocktail synthesis. The module and parameter settings of the instrument were set as shown in Table S1. In each quality control process, we first fixed the amount of exosomes and used different amounts of let-7a mimics. Thus, the amount of let-7a mimics corresponding to the highest NNs synthesis rate was the maximum amount that could be loaded, and this amount or below was optional.

As shown in Figure 2e, for instance, we used fixed amounts of NKEXOs $10 \mu \mathrm{g}$ and varied the amount of let-7a mimics and the synthesis time. Using HCS screening, we observed that the coupling efficiency of NNs increased over time and reached a peak of nearly $59.67 \%( \pm 6.69 \%)$ at $24 \mathrm{~h}$. In contrast, the highest NNs synthetic rate was observed when the amount of the let-7a mimics was $0.13 \mu \mathrm{g}(10 \mu \mathrm{L}$ at $1 \mu \mathrm{M}$ concentration; Figure $2 \mathrm{f}$ ). This was considered the maximum rate to prepare a single batch of the NN/NKEXO cocktail over a $24 \mathrm{~h}$ period. All the cocktails used in this study were subject to the same progress to ensure that NKEXOs are excess at any time. 
a

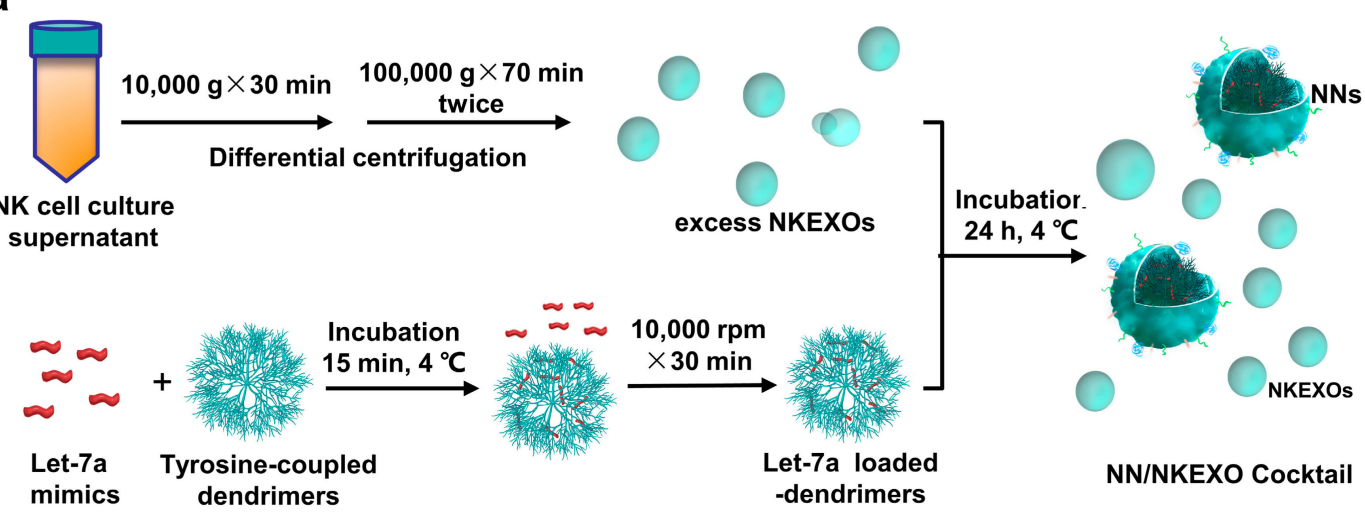

b

C
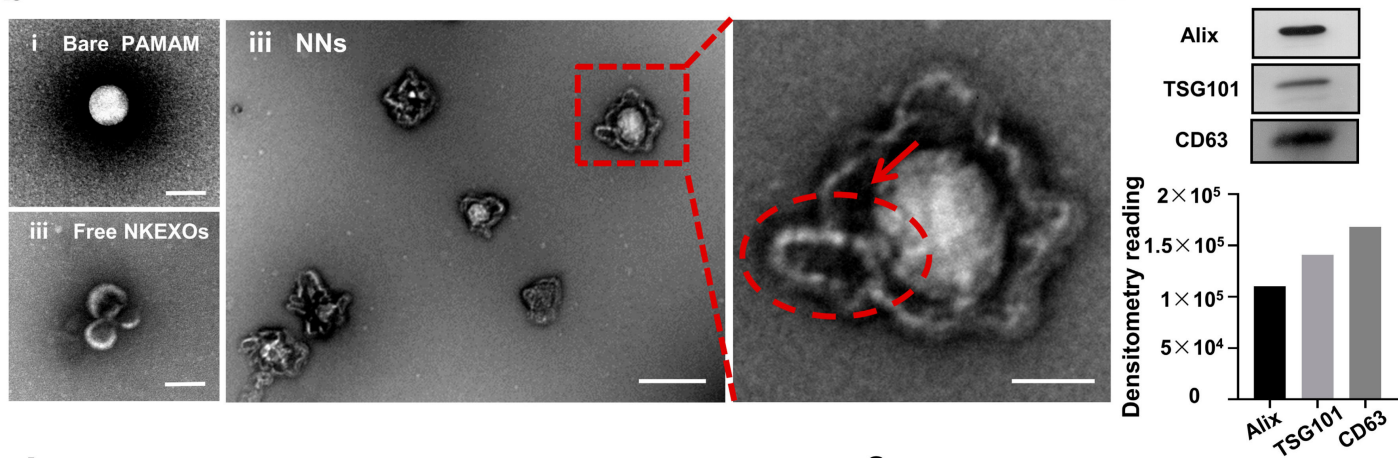

d

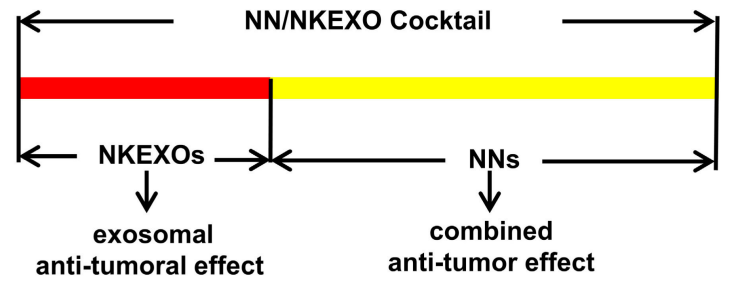

e
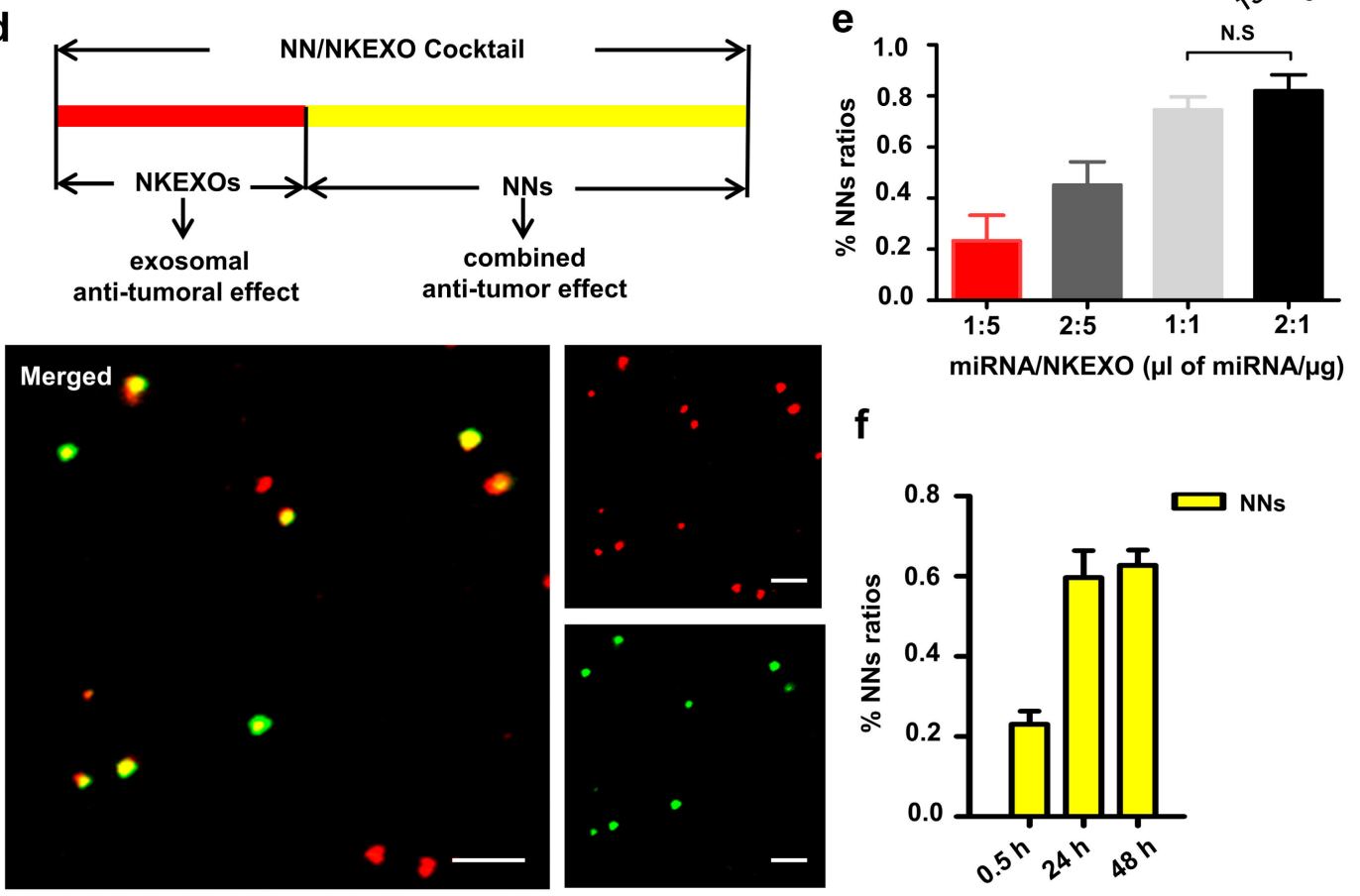

$\mathbf{f}$

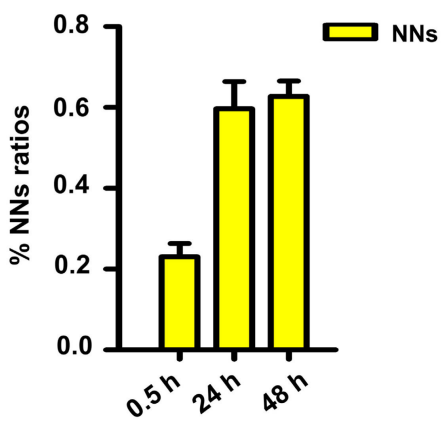

Figure 2. Fabrication and characterization of the NN/NKEXO cocktail. (a) Schematic design of the NN/NKEXO cocktail. (b) TEM images of bare PAMAM dendrimers (i), NNs (ii) and free NKEXO in supernatant (iii). The arrow indicates an integrated NKEXO. (c) NNs contain typical intracellular proteins markers (ALIX, TSG101), confirmed by Western blot (WB). (d) CLSM images of the fabricated NN/NKEXO cocktail illustrating the colocalization of let-7a loaded dendrimers (green) and NKEXO (red). (e) Percentages of NNs in the NN/NKEXO cocktail at different miRNA to NKEXO ratios. (f) Percentages of NNs in NNs-NKEXO cocktail at different synthesis times at a 1:1 miRNA to NKEXO ratio. 


\subsection{Binding and Cytotoxicity of the NN/NKEXO Cocktail to a Human Neuroblastoma Cell Line In Vitro}

Next, we evaluated the nanoparticle cocktail kinetics in human neuroblastoma CHLA-255 cells at different incubation times with the dual labeled cocktail (miRNA loaded dendrimers: FAM, green and NKEXOs: PKH-26, red), followed by observation via CLSM. As shown in Figure 3a, the internalization of both NKEXOs and let-7a inside tumor cells increased from 12 to $24 \mathrm{~h}$. Additional quantitative measurements were performed using flow cytometry. Equivalent exosomes derived from human embryonic kidney cell line 293T were obtained and 293N/293EXO cocktail was synthesized as control. The fluorescence intensity of let-7a mimics in CHLA-255 cells increased along with the NKEXO fluorescence in a time-dependent manner. Neither fluorescence intensities weakened until cells were incubated for at least $48 \mathrm{~h}$. Importantly, CHLA-255 cells treated with the NN/NKEXO cocktail showed a prominent right shift in the cytometric analysis, suggesting a higher cellular uptake of exosomes than 293N/293EXO cocktail (Figure 3b). Furthermore, more CHLA-255 cells internalized miRNA, with the mean fluorescence intensity value higher than in the control cocktail at any time point (Figure 3c,d). This indicates that the NKEXO based outer shell plays a critical role in improving the cancer target drug delivery efficiency. We also used the bioluminescence assay to substantiate the synergistic apoptosis-inducing capability of the cocktail in vitro. Since let-7a, a therapeutic microRNAs, is closely involved in the proliferation of neuroblastomas [34,35]. As shown in Figure 3e, after $24 \mathrm{~h}$ of incubation, NN/NKEXO cocktail-let-7a exhibited significantly higher cytotoxicity compared with NKEXO alone in neuroblastoma cells. In contrast, no significant inhibition of cell growth was observed in let-7a or dendrimers treated groups, indicating that the NNs mediated delivery of therapeutic let-7a enhances the anti-tumor effect of the cocktail by triggering a synergistic induction of apoptosis. 
a

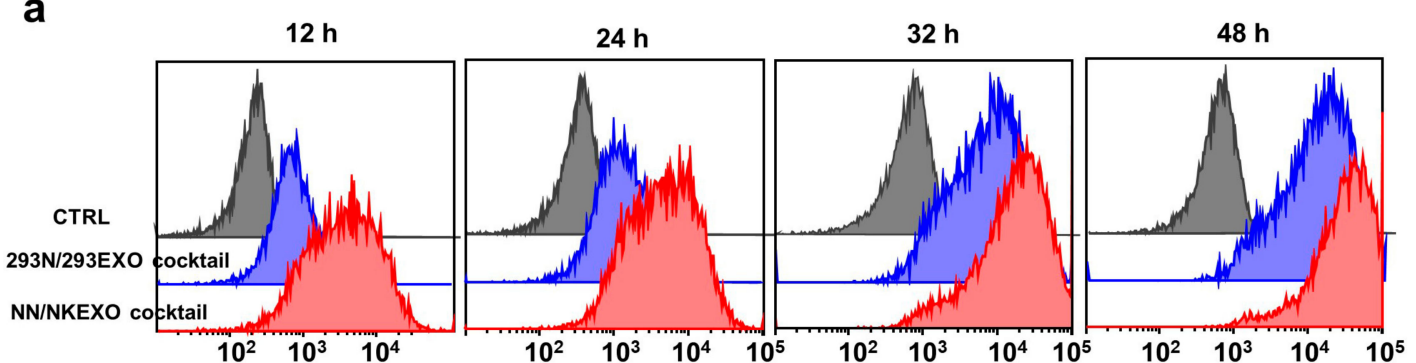

b

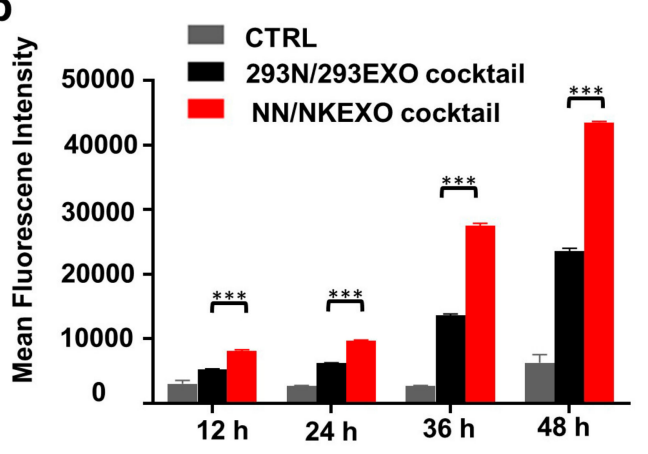

C
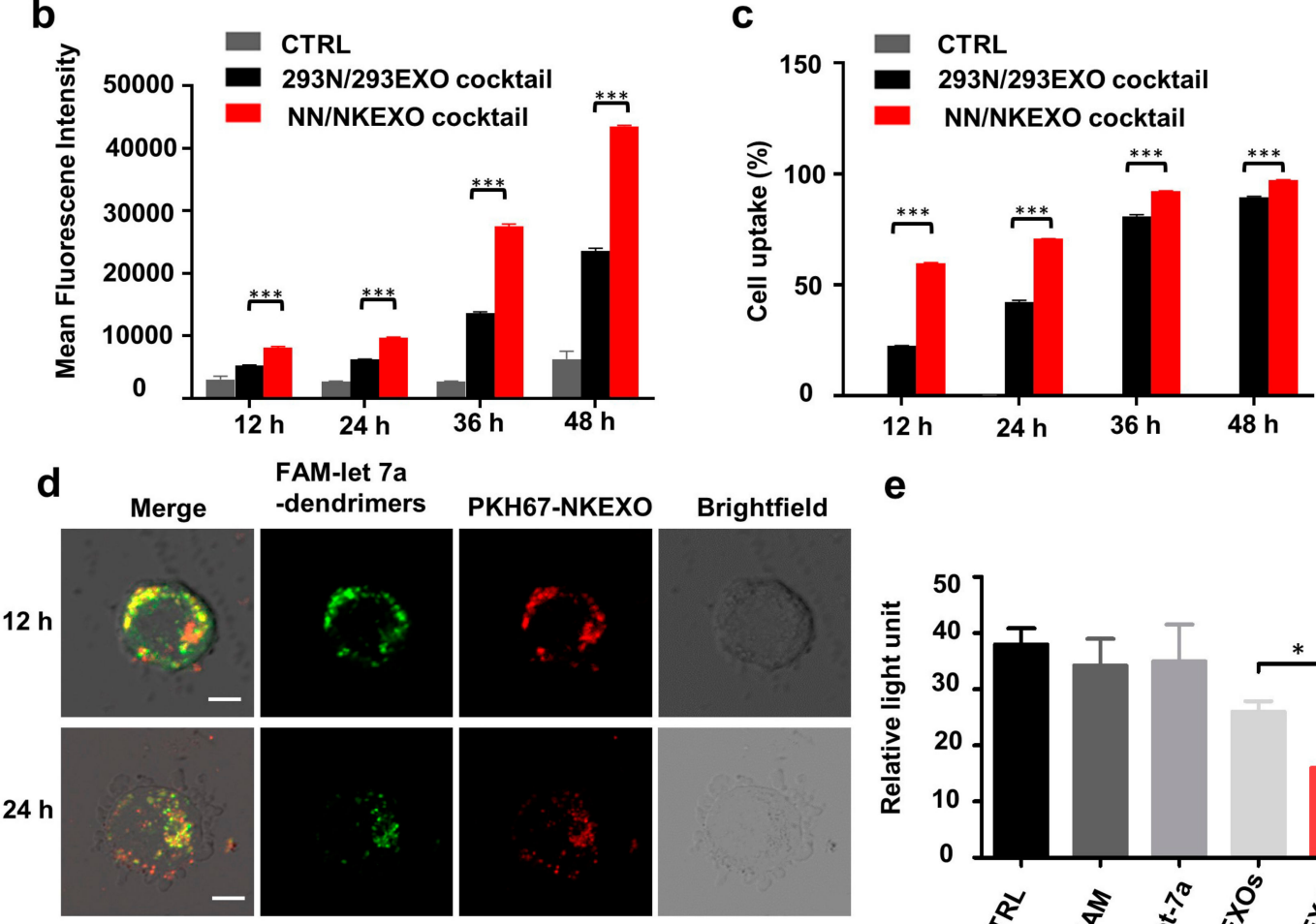

e

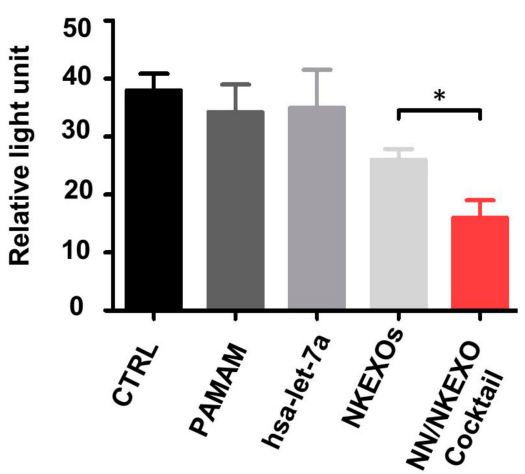

Figure 3. Binding and cytotoxicity of the NN/NKEXO cocktail to a human neuroblastoma cell line in vitro. (a) Representative confocal fluorescence images of CHLA-255 cells after treatment with NN/NKEXO cocktail for 12 and 24 h (let-7a-dendrimer: Green; NKEXO: Red). (b) Quantitative flow cytometric analysis of CHLA-255 cells incubated with control medium, 293N-293Exo cocktail and NN/NKEXO cocktail both made of let-7a $(0.5 \mu \mathrm{g})$ and their exosomes $(50 \mu \mathrm{g})$ for 12, 24, 36 and $48 \mathrm{~h}$; $n=3$. (c) Mean fluorescence intensity of CHLA-255 cells after 12, 24, 36 or $48 \mathrm{~h}$ incubation with control medium and different cocktails; $n=3$. (d) Percentages of cells with increased miRNA fluorescence; $n=3$. (e) Cell viability of CHLA-255 cells ( $10^{4}$ cells per well) after treatment with PBS (CTRL), PAMAM, let-7a, NKEXOs and NN/NKEXO cocktail ( $40 \mu \mathrm{g}$ NKEXOs and $0.05 \mu \mathrm{g}$ let-7a) for $24 \mathrm{~h}$. Data are presented as mean $\pm \mathrm{SD} ; n=3$.

\subsection{In Vivo Biodistribution and Anti-Tumor Effect of the NN/NKEXO Cocktail}

To evaluate the tumor targeting capability of the cocktail, let-7a was labeled with Cy5 and the cocktail was administrated intravenously into the CHLA-255-luc tumor-bearing nonobese diabetic/severe combined immunodeficient (NOD/SCID) mice. After removal of the tumors and organs of interest $6 \mathrm{~h}$ after injection, ex vivo fluorescence imaging showed strong fluorescence signals of let-7a loaded dendrimers in the tumor tissues and relatively strong signals in the kidneys. In contrast, no specific fluorescence was detected in tumor tissues of mice treated with miRNA alone or miRNA loaded dendrimers (Figure 4a). These results indicate that the NN/NKEXO cocktail have highly 
efficient targeting and miRNA delivery to tumor cells. NKEXOs showed tumor-specific accumulation as early as $24 \mathrm{~h}$ post-injection in vivo [6]. Here, we labeled NKEXOs with DiR (red) to prepare the cocktail administrated intravenously. Interestingly, using ex vivo fluorescence imaging (Figure 4b), NKEXOs showed tumor-specific accumulation as early as $6 \mathrm{~h}$ post-injection. In the second method, a subcutaneous tumor mice model was used. The dual fluorescently labeled cocktail (let-7a loaded dendrimers: FAM, green and NKEXOs: PKH-26, red) was intravenously injected. As demonstrated by two-photon excited scanning fluorescence imaging (TPEFI), miRNA loaded dendrimers were found in the tumor tissues as early as $20 \mathrm{~min}$ after administration (Figure 4c; Video S2). These results indicate that our cocktails are suitable for highly efficient tumor-targeted delivery. In this regard, CXCR4 presence in NKEXOs has been shown which intimately linked to the accumulation at specific organs, and CD47 presence is a "don't eat me" signal for phagocytic cells to achieve longer circulation times (Figure 4d) [36-38]. Both molecules potentially promoted NNs to target primary tumors and organ specific metastasis more accurately and actively.

Finally, we evaluated the in vivo antitumor effect of the cocktails. Mice bearing tumors induced by CHLA-255-luc cells were randomly sorted into five groups ( $n=3$ per group). As indicated in Figure 4e, a pronounced suppression of tumor growth was observed in the animals treated with cocktail-let-7a. Notably, the signal intensity of the cocktail treatment group was significantly lower than that of the NKEXO group $(p<0.05)$, further indicating that the let-7a was efficiently and successfully carried to tumor cells by NNs and exerted a synergistic antitumor effect with NKEXOs (Figure 4f,g). 
a

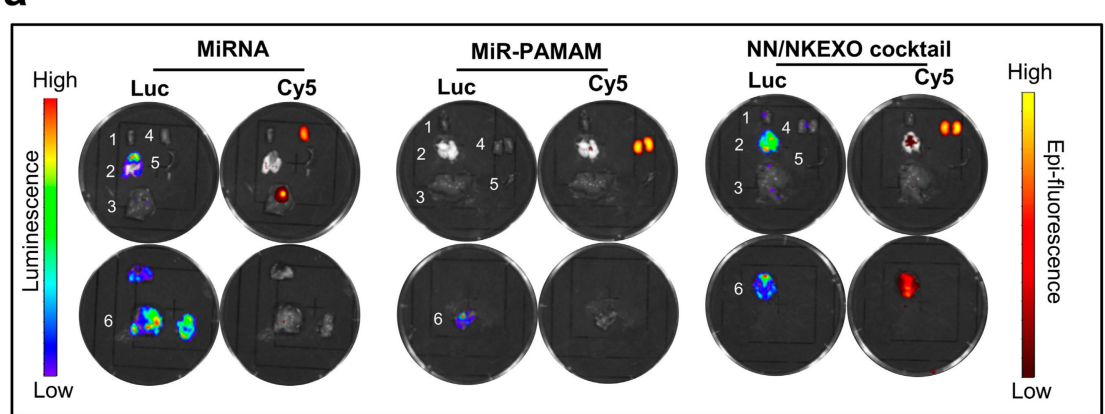

b

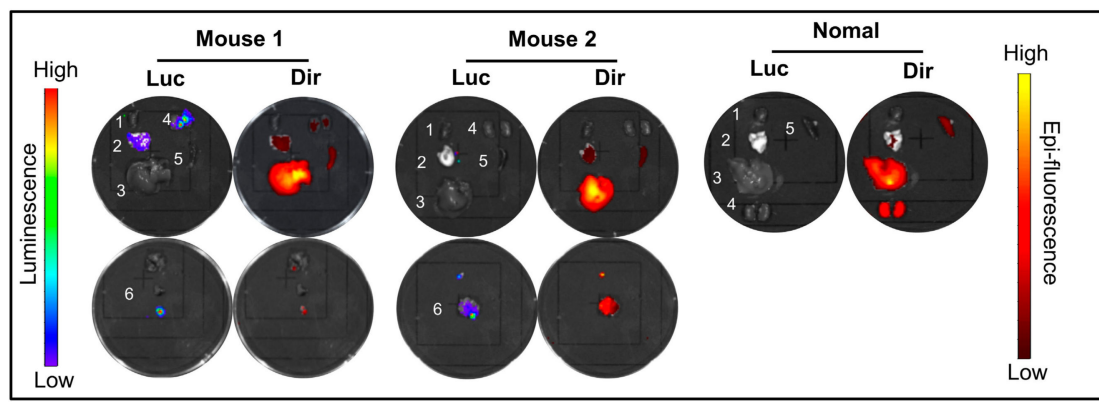

C

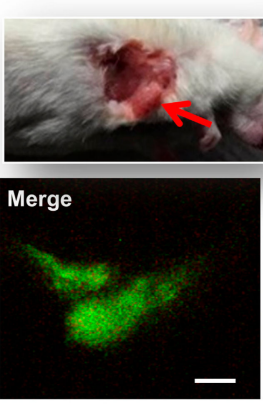

FAM-hsa-let-7a

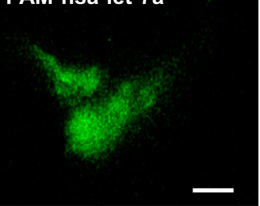

PKH67-NKEXOS d

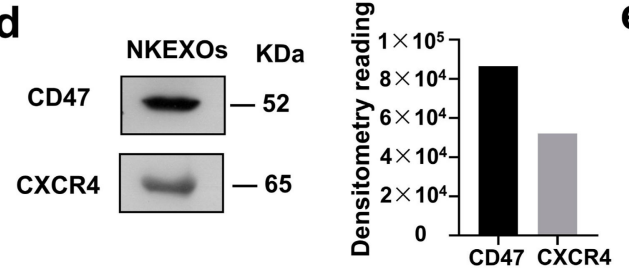

e

CHLA-255 Flu_NOD/SCID mice

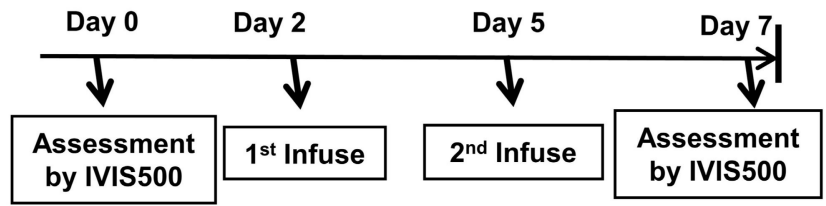

f

PBS

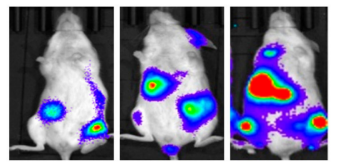

PAMAM

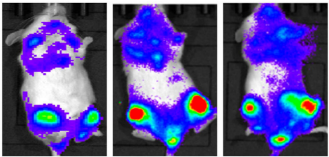

hsa-let-7a

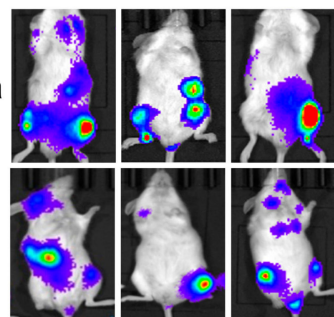

NN/NKEXO cocktail
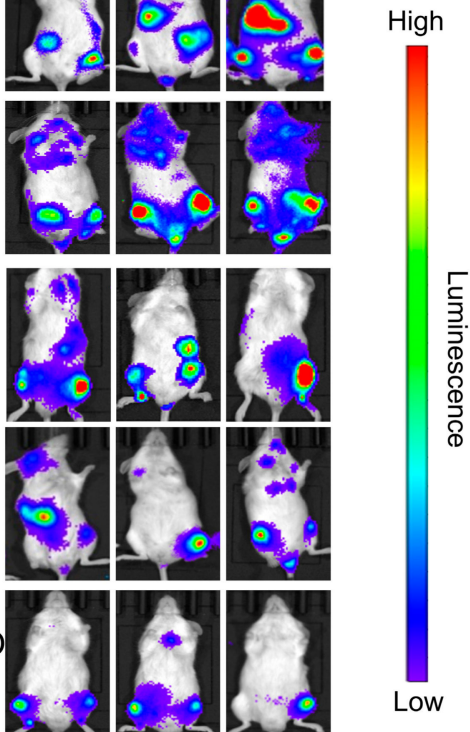

g

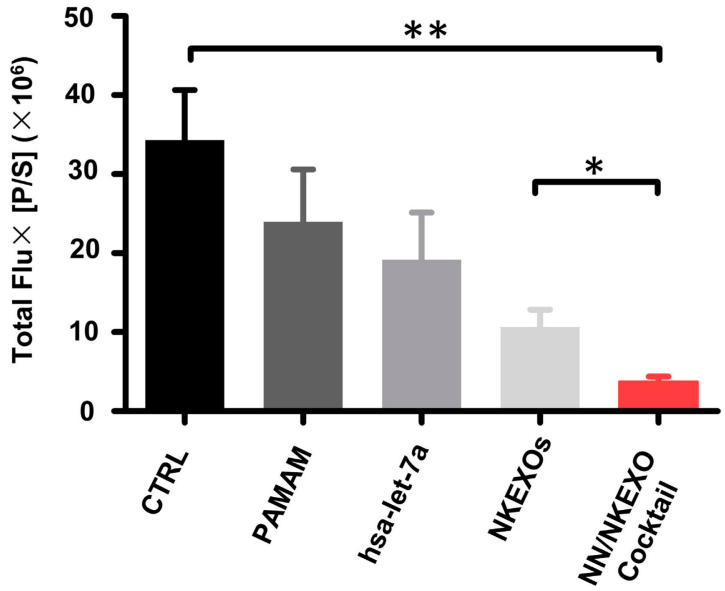

Figure 4. In vivo biodistribution and anti-tumor effect of the NN/NKEXO cocktail. (a) Bioluminescence (Luc) and miRNA fluorescence (Cy5) images of major organs of the NOD/SCID mice bearing systemic CHLA-255-luc tumors $6 \mathrm{~h}$ after intravenous (i.v.) injection of Cy5-let-7a, Cy5-let-7a-dendrimers and Cy5-labeled NN/NKEXO cocktail: 1) Heart; 2) lung; 3) liver; 4) kidney; 5) spleen and 6) tumor. 
(b) Bioluminescence (Luc) and fluorescence images of major organs $6 \mathrm{~h}$ after i.v. injection of DiR-labeled NN/NKEXO cocktail made of $5.28 \mu \mathrm{g}$ of let-7a and $100 \mu \mathrm{g}$ of NKEXOs. (c) In vivo two-photon excitation fluorescence images of the CHLA-255 ${ }^{\text {luc }}$ subcutaneous tumor model 20 min after i.v. injection of $400 \mu \mathrm{L}$ dual fluorescently labeled NN/NKEXO cocktail made of $5.28 \mu \mathrm{g}$ of let-7a and $100 \mu \mathrm{g}$ of NKEXOs. (d) Expression of functional proteins (CD47 and CXCR4) was confirmed by WB. (e) Experimental protocol for CHLA-255luc-NOD/SCID mice shown in (f). (f) Bioluminescence imaging (BLI) performed in CHLA-255 luc -NOD/SCID mice treated with different cocktail formulations at let-7a dose of $5.28 \mu \mathrm{g}$ and NKEXO dose of $100 \mu \mathrm{g}(n=3)$. (g) Quantification of BLI results. Each bar represents mean \pm SD of three replicates. ${ }^{*} p<0.05$ and ${ }^{* *} p<0.001$.

\section{Discussion}

An ideal nanomedicine for cancer therapy should elicit minimal immunogenicity. In the traditional membrane preparation processes, the use of integrated NKEXOs as shells of nanoparticles avoids potential contamination with immunogenic substances. The advantage of NK cells, a source of NKEXOs, is that it can act as an off-the-shelf product for allogeneic settings [27]. NKEXOs also exhibit the benefits of being stable vesicles that maintain their biological activities for at least two years at $-80{ }^{\circ} \mathrm{C}$ [39]. These properties make them more suitable for clinical applications.

Although the exact mechanisms by which NKEXOs specifically target tumors are not clear, the following clues may explain this targeting and guide further research in this area. CXCR4 is one of the best-characterized chemokine receptors mediating leukocyte trafficking [40]. Moreover, its ligand, SDF-1a, is released in large amounts by some tumor or organs, such as the lung and liver [36,37]. The interaction between SDF-1 and CXCR4 also plays an important role in cancer metastasis [41,42]. NKEXOs, expressing CXCR4 as determined in our study, likely induced NNs to leave systemic circulation and traffic into tumors or organs. In this context, NNs had the potential to become "prophylactic" anti-metastatic agents.

However, we note that in our experiments the number of experimental animals was relatively small with a short observation period. Besides, more details of the coating progress from a chemical standpoint were not provided.

Given the distinct advantage of being easy to generate and having good clinical application prospects, we believe further research in this field will resolve the aforementioned limitations. To this end, this cocktail strategy is expected to offer new opportunities for the advancement of cancer nanomedicine.

\section{Materials and Methods}

\subsection{Cell Culture}

The human breast cancer cell lines MDA-MB-231 and human embryonic kidney cell lines 293T were propagated in DMEM (Gibco, Grand Island, NY, USA) supplemented with 10\% FBS (Gibco) and $1 \%$ penicillin-streptomycin (Hyclone, Logan, UT, USA). Human neuroblastoma cells CHLA-255 were incubated in IMDM (Gibco) with 20\% FBS and 1\% penicillin-streptomycin. All cell lines were purchased from the American Type Culture Collection (ATCC). Both MDA-MB-231 and CHLA-255 cells were transfected by Nucleofection ${ }^{\mathrm{TM}}$ (Lonza, Cologne, Germany) with a firefly luciferase expression plasmid. All cells were maintained in a humidified $5 \% \mathrm{CO}_{2}$ atmosphere at $37^{\circ} \mathrm{C}$.

\subsection{Preparation and Function of NK Cell Derived Exosomes}

\subsubsection{Isolation of Exosomes}

We isolated NK cell-derived exosomes using differential ultracentrifugation according to the literature. On day 21, NK cell culture supernatants were harvested after a preliminary centrifugation at $400 \times \mathrm{g}$ for $10 \mathrm{~min}$ to eliminate cells. The supernatants were centrifuged first at $2000 \times \mathrm{g}$ for $10 \mathrm{~min}$ and then at $10,000 \times \mathrm{g}$ for $70 \mathrm{~min}$ to remove dead cells and cell debris, followed by an additional 
centrifugation step at 100,000 $\times \mathrm{g}$ for $70 \mathrm{~min}$ in a 70Ti ultracentrifuge rotor (Optima ${ }^{\mathrm{TM}} \mathrm{XPN}-100$, Beckman, Brea, CA, USA) to obtain pellets containing raw exosomes. The pellets were then purified by washing them with PBS and centrifuged at 100,000 $\times \mathrm{g}$ for another $70 \mathrm{~min}$. The isolated exosomes were resuspended in PBS (100:1 enrichment) and stored at $-80^{\circ} \mathrm{C}$ before use. All procedures were carried out at $4{ }^{\circ} \mathrm{C}$. We isolated exosomes from the $293 \mathrm{~T}$ culture medium in the same way.

\subsubsection{Measurement of Particle Size}

A dynamic light scattering (DLS) system equipped with a 532-nm laser (Malvern Instruments, Malvern, UK) was used for exosome particle size analysis. Samples were diluted before analysis $(10 \mu \mathrm{L}$, 1:100 diluted in PBS) and each sample was measured three times. Data was collected and analyzed by Dispersion Technology Software (Malvern Instruments). The size distribution was measured by signal intensity and the Z-average diameter obtained from the autocorrelation function using the general-purpose mode.

\subsubsection{Determination of Protein Concentration}

Protein concentration in isolated exosomes was calculated by the bicinchoninic acid protein assay. Briefly, $25 \mu \mathrm{L}$ of an aqueous suspension of isolated exosomes after lysis were added to $200 \mu \mathrm{L}$ of standard working reagent in wells of a 96-well plate. Absorbance of the mixture was determined at $562 \mathrm{~nm}$ with a microplate reader and the protein concentration estimated. A calibration curve was constructed using bovine serum albumin as protein standard.

\subsubsection{Western Blotting (WB) Analysis}

Presence of marker proteins in exosomes was analyzed and confirmed by WB. Proteins from lysed cells or isolated exosomes were denatured and loaded onto sodium dodecyl sulfate polyacrylamide gels, transferred to polyvinylidene difluoride membranes (Millipore, Billerica, MA, USA), and subsequently stained with the corresponding primary and secondary antibodies. The following antibodies were used for WB analysis according to manufacturer's instructions: Anti-ALIX polyclonal antibody (12422-1-AP, Proteintech, Rosemont, IL, USA), anti-CD47 polyclonal antibody (ab108415, Abcam, Cambridge, MA, USA), anti-CXCR4 polyclonal antibody (35-8800, Invitrogen, Waltham, MA, USA ), anti-TSG101 monoclonal antibody (4A10, Abcam), anti-human CD63 polyclonal antibody (556019, BD Biosciences) and anti-cytochrome C antibody (10993-1-AP, Proteintech). The BioRad ChemiDoc Touch imaging system (BioRad, Hercules, CA, USA) was used to analyze the bands after incubation with the corresponding goat anti-mouse- or goat anti-rabbit-HRP secondary antibody conjugates (1:5000 dilutions). The densitometry readings of each band were calculated by ImagJ (NIH, Bethesda, MD, USA).

\subsubsection{Transmission Electron Microscopy (TEM)}

Morphology of the isolated NKEXOs was studied by TEM. A small drop (about $10 \mu \mathrm{L}$ ) of exosomes was dropped onto the Formvar/carbon-coated TEM grid. After settling for approximately $1 \mathrm{~min}$, excess water was removed by touching the grid with a piece of filter paper. Next, the grid was covered with a small drop of $2 \%$ uranyl acetate. After drying for ten seconds, the copper nets were examined with a Tecnai T10 TEM (FEI, Oregon, OH, USA) operated at $120 \mathrm{kV}$. The morphology of the PAMAM dendrimers and NNs was also imaged by TEM following similar steps.

\subsubsection{Samples Labeling}

To label isolated exosomes and let-7a loaded PAMAM, different labeling assays were performed. We added $2 \mu \mathrm{L}$ of red lipophilic fluorescent dye PKH26 (Sigma-Aldrich, St. Louis, MO, USA) to $500 \mu \mathrm{L}$ of Diluent C (Sigma-Aldrich). The mixture was then added to the isolated NK derived exosomes and mixed gently for $5 \mathrm{~min}$ at room temperature followed by addition of $1 \%$ BSA 
(1 mL) to facilitate the binding of the excess dye. Next, samples were washed with PBS and ultracentrifuged at 100,000 $\mathrm{g}$ for $70 \mathrm{~min}$ and the pellets resuspended in PBS. The fluorescent dye 1,10-dioctadecyl-3,3,30,30-tetramethylindotricarbocyanine iodide (DiR; Invitrogen) was also used to label exosomes. Purified exosomes were incubated in $1 \mu \mathrm{M}$ DiR at a concentration of approximately $350 \mu \mathrm{g}$ of exosomes per $\mathrm{mL}$ for $15 \mathrm{~min}$ at $37^{\circ} \mathrm{C}$, and washed as described above. FAM-labeled miRNA and cy5-labeled miRNA were both synthesized by Genepharma (Shanghai, China).

\subsection{Cellular Uptake Assay}

PKH26-labeled NKEXOs were incubated with MDA-MB-231 cells for $24 \mathrm{~h}$ in a humidified $5 \% \mathrm{CO}_{2}$ atmosphere at $37^{\circ} \mathrm{C}$. Subsequently, cells were washed twice with PBS and fixed with $4 \%$ paraformaldehyde for $20 \mathrm{~min}$. Aliquots $(5 \mu \mathrm{L})$ of the cell suspension were placed in clear microscope slides, covered with a drop of FluorSave ${ }^{\mathrm{TM}}$ Reagent (Invitrogen) and mounted with a coverslip. Images, including z-axis projection images, were taken using a Nikon A1R (Nikon instruments, Melville, NY, USA) confocal laser scanning microscope. The uptake of the NN/NKEXO cocktail by CHLA-255 cells was also imaged following similar steps after incubating for 12 and $24 \mathrm{~h}$.

\subsection{Flow Cytometry}

FAM-labeled let-7a loaded PAMAM and PKH26-labeled NKEXOs were coupled to fabricate the nanoparticle cocktail as indicated before. To quantify the cellular uptake of the cocktail by tumor cells, CHLA-255 cells $\left(10^{5}\right.$ cells per well) were cultured with the NN/NKEXO cocktail made of let-7a $(0.5 \mu \mathrm{g})$ and NKEXOs (50 $\mu \mathrm{g}$ ), PBS or equivalent 293N/293Exo cocktail between 12 to $48 \mathrm{~h}$, harvested, and washed twice with PBS. Then, the samples were centrifuged and the supernatants decanted. Cells were resuspended and collected before analysis with a Cytoflex flow cytometer (Beckman Coulter, Life Science, Indianapolis, IN, USA).

\subsection{Preparation of the NN/NKEXO Cocktail}

To prepare NN/NKEXO cocktails in this study, 0.05/0.5/5.28 $\mu \mathrm{g}$ let-7a mimics (Genepharma) were added to dendrimers following manufacturer's instructions (SL100568, SignaGen Laboratories, Rockville, MD, USA) and mixed thoroughly to react at $4{ }^{\circ} \mathrm{C}$ for $15 \mathrm{~min}$. The resulting let-7a loaded PAMAM were precipitated at high-speed $(10,000 \mathrm{rpm})$ for $30 \mathrm{~min}$ to remove excess let-7a. Subsequently, 40/50/100 $\mu \mathrm{g}$ of NKEXOs suspension were added to the precipitated let-7a loaded PAMAM respectively and the mixture incubated for 24 hours at $4{ }^{\circ} \mathrm{C}$. To obtain NNs, the NN/NKEXO cocktail was precipitated at high-speed (10,000 rpm) for $30 \mathrm{~min}$ and resuspended in PBS. The supernatants with excess NKEXOs were used for TEM and the precipitated NNs for both Western blotting analysis and TEM. The same procedure was used in fabricating another cocktail in this study.

Confocal laser scanning microscopy (Nikon A1R) was used to validate whether NKEXOs were successfully fused with the let-7a loaded-PMAM. Exosomes and let-7a mimics were fluorescently labeled by PKH26 and FAM, respectively. Laser excitation of PKH67 and FAM was done sequentially using 586- and 488-nm lasers.

\subsection{In Vitro Cytotoxicity}

To evaluate NKEXO cytotoxicity, MDA-MB-231 breast cancer cells and CHLA-255 neuroblastoma cells were transfected with the firefly luciferase gene to quantify target cell survival using bioluminescence. MDA-MB-231-luc and CHLA-255-luc cells $\left(10^{4}\right.$ cells per well) were cultured with different quantities of NKEXOs (10, 20 and $40 \mu \mathrm{g}$ ) in clear-bottomed 96-well plates for $24 \mathrm{~h}$. The culture medium was discarded and cells washed with PBS three times, followed by the addition of $120 \mu \mathrm{L}$ of cell lysis buffer from a luciferase reporter Gene Assay kit (Yisheng, Shanghai, China). The 96-well plates were then shaken in a micro-shaker at room temperature for $15 \mathrm{~min}$ to fully lyse the cells. Next, the pyrolyzed lysates were centrifuged at $10,000 \mathrm{rpm}$ for 3-5 minutes. After centrifugation, $100 \mu \mathrm{L}$ of the supernatants from each well were transferred to a clear-bottomed 96-well plate, and $100 \mu \mathrm{L}$ 
of firefly luciferase assay reagent added. Bioluminescent signals of the mixture were measured by the IVIS ${ }^{\circledR}$ Lumina III imaging system (PerkinElmer, Santa Clara, CA, USA) and expressed as photon flux (photons/s). All experiments were done in triplicate from independent cell cultures.

To evaluate the cytotoxicity of cocktail-let-7a against the neuroblastoma cells in vitro, CHLA-255-luc cells ( $10^{4}$ cells per well) were treated with NKEXOs, let-7a alone or cocktail-let-7a containing $40 \mu \mathrm{g}$ NKEXOs and $0.05 \mu \mathrm{g}$ let-7a. Bioluminescent signals of the mixture were measured by an automatic ELISA plate reader and the relative light unit read at $562 \mathrm{~nm}$.

\subsection{In Vivo Animal Experiments}

In vivo analysis was performed using specific pathogen-free, 6-week-old, female NOD/SCID mice (Slaccas, Shanghai, China). All animal experimental protocols were conducted in accordance with all national guidelines and regulations, and approved by the Animal Ethics Committee (NO. 2018R03042).

\subsubsection{In Vivo Targeting Capability of the Nanoparticle Cocktail}

The cocktail was labeled with Cy5-let-7a loaded PAMAM or DiR-NKEXOs. Then, $5 \times 10^{6}$ CHLA255 cells were intravenously injected into mice, which were randomly separated into four groups after 21 days in captivity. Animals in one group received intravenous injections containing $400 \mu \mathrm{L}$ of labeled cocktail with identical amounts of let-7a $(5.28 \mu \mathrm{g})$ and NKEXOs $(100 \mu \mathrm{g})$. A second group received let-7a loaded PAMAM and the third group received let-7a only. At the end of the experiment ( $6 \mathrm{~h}$ after injection), the mice were euthanized and dissected tissues (heart, lung, liver, kidneys, spleen, livers and tumors) were imaged immediately. Fluorescence imaging was performed using the IVIS ${ }^{\circledR}$ Lumina III imaging system. Background fluorescence was measured and subtracted by setting up a background measurement at time of data acquisition. A separate in vivo biodistribution study was performed using the following procedure. CHLA-255-luc cells $\left(2 \times 10^{7}\right.$ cells/200 $\left.\mu \mathrm{L}\right)$ were subcutaneously injected into the forward thighs of NOD/SCID mice. After 14 days, the mice were anesthetized and the subcutaneous tumor tissue was carefully exposed using surgical scissors. Mice were injected intravenously with $400 \mu \mathrm{L}$ of a cocktail made of FAM-labeled miRNA let7a (5.28 $\mu \mathrm{g})$ and PKH26-labeled NKEXOs (100 $\mu \mathrm{g})$. After $20 \mathrm{~min}$, in vivo two-photon confocal microscopy (Olympus BX61, Olympus America, Center Valley, PA, USA) was performed to detect each fluorescence signal from the subcutaneous tumor.

\subsubsection{In Vivo Antitumor Assay}

The ability of the cocktail to inhibit tumor growth was evaluated in a neuroblastoma tumor-bearing mouse model. Fifteen mice were used in this experiment. Briefly, CHLA-255-luc cells ( $10^{7}$ cells/500 $\left.\mu \mathrm{L}\right)$ were i.v. injected into the NOD/SCID mice. Mice were randomly separated into five groups $(n=3)$ 14 days later, and intravenously injected with different cocktail formulations: NKEXOs, cocktail-let-7a, PAMAM, let7a or with PBS as control group at let-7a dose of $5.28 \mu \mathrm{g}$ and NKEXO dose of $100 \mu \mathrm{g}$. The same treatments were repeated after three days. After treatment, bioluminescence imaging (BLI) was performed with the IVIS ${ }^{\circledR}$ Lumina III imaging system to analyze the cocktail's therapeutic effect.

\subsection{Statistics}

Data are expressed as mean \pm SD. SPSS Statistics 24 software (IBM, Armonk, NY, USA) and GraphPad Prism 5 software (GraphPad Software, Inc., San Diego, CA, USA) were used to perform data analysis using the analysis of variance (ANOVA) function. $p<0.05$ values were considered statistically significant.

\section{Conclusions}

In summary, we reported the novel strategy for tumor targeting therapy based on NN/NKEXO cocktail. As displayed in Figure 5, the NNs constituted a novel biomimetic core-shell polymer, formed 
by the self-assembly of two components: (1) A PAMAM dendrimer-based inner core part for loading gene therapeutic agents and (2) the NKEXO based outer shell facilitating tumor targeting and acting as a direct antitumor agent. The NKEXOs coating guided NNs to the tumor and interacted with the plasma membrane of the target cells via endocytosis/fusion or via FasL/Fas. Finally, the therapeutic miRNA was released and regulated the transcriptome batch or gene of the cell, which performed a combined anti-tumoral effect with NKEXOs.

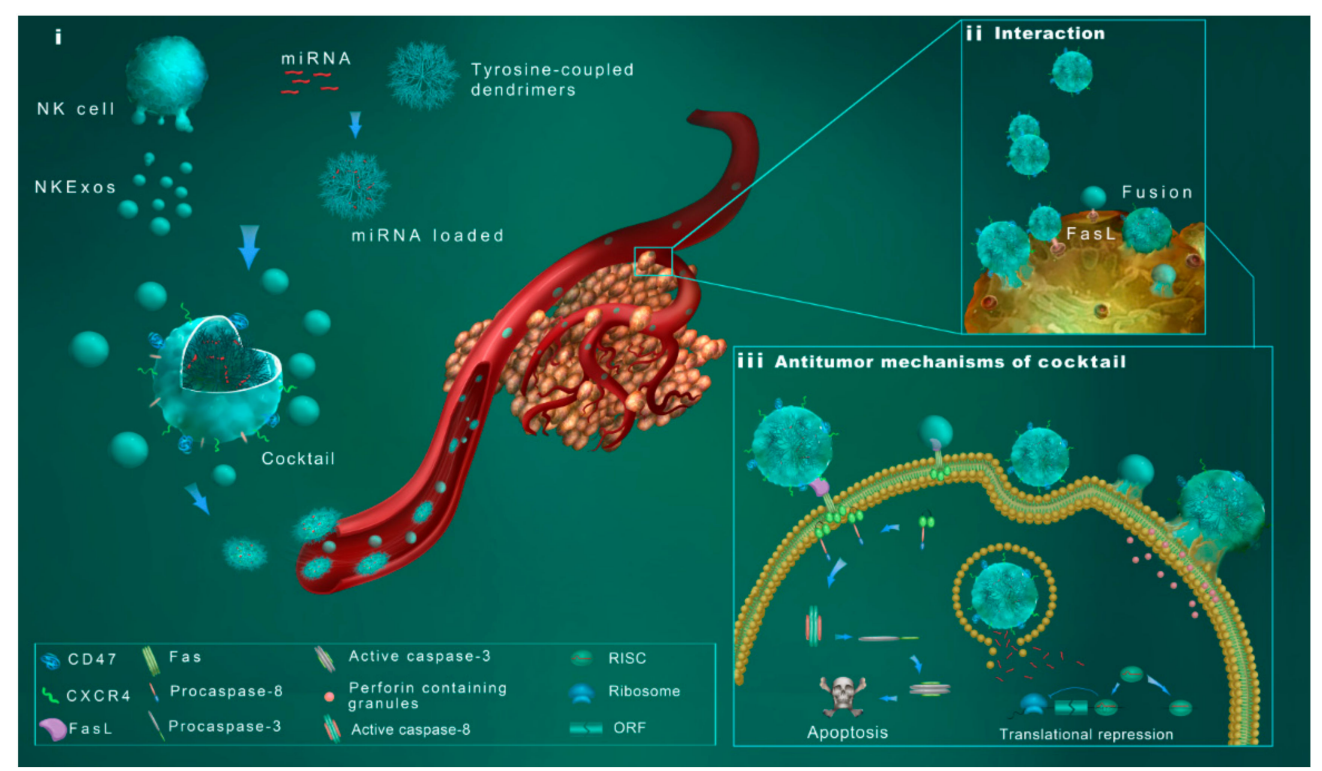

Figure 5. Schematic design of the NN/NKEXO cocktail for tumor targeting and drug delivery. (i) Main components of the cocktail: exosomes derived from NK cells (NKEXOs); exosome camouflaged core-shell nanoparticles (NNs). CD47 and CXCR4 facilitate a more accurate and active delivery of NNs. (ii) Interaction of the nanoparticle cocktail with target cells. Both NKEXOs and NNs are involved in exosome-to-membrane fusion and receptor-ligand interaction. (iii) Mechanisms of cocktail antitumor effect include perforin/granzyme mediated apoptosis, FasL/Fas mediated apoptosis and the effect of released therapeutic miRNA.

Supplementary Materials: The following are available online at http://www.mdpi.com/2072-6694/11/10/1560/s1, Figure S1: Confocal laser scanning microscopy examination of MDA-MB-231 cellular uptake of NKEXOs; Table S1: Parameters of high-content screening (HCS) analysis; Video S1: A rotating 3D rendering of z-stack images showing the internalization of NKEXOs into MDA-MB-231-luc cells; Video S2: Fluorescence signal of NN/NKEXO cocktail detected in the tumor tissues using TPEFI.

Author Contributions: Conceptualization, G.W. and Y.X.; methodology, G.W., W.H. and H.C.; software, T.Y.; validation, G.W., W.H., H.C., X.S., T.Y. and Y.X.; formal analysis, G.W., W.H. and H.C.; investigation, G.W., W.H., H.C and X.S.; resources, Y.X.; data curation, G.W., W.H., X.S. and T.Y.; writing-original draft preparation, G.W.; writing-review and editing, W.H. and Y.X.; visualization, G.W. and W.H.

Funding: This research was funded by the Startup Foundation for Talented Scholars of Zhejiang University, grant number 119000-193820101.

Acknowledgments: We acknowledge the technical support by the Core Facilities, Zhejiang University School of Medicine.

Conflicts of Interest: The authors declare no conflict of interest.

\section{References}

1. Langer, R. Drug delivery and targeting. Nature 1998, 392, 5-10.

2. Allen, T.M.; Cullis, P.R. Drug delivery systems: Entering the mainstream. Science 2004, 303, 1818-1822. [CrossRef] [PubMed]

3. Mura, S.; Nicolas, J.; Couvreur, P. Stimuli-responsive nanocarriers for drug delivery. Nat. Mater. 2013, 12, 991-1003. [CrossRef] [PubMed] 
4. Tomalia, D.A.; Baker, H.; Dewald, J.; Hall, M.; Kallos, G.; Martin, S.; Roeck, J.; Ryder, J.; Smith, P. A new class of polymers: Starburst-dendritic macromolecules. Polym. J. 1985, 17, 117. [CrossRef]

5. Wagner, E. Strategies to improve DNA polyplexes for in vivo gene transfer: Will "artificial viruses" be the answer? Pharm. Res. 2004, 21, 8-14. [CrossRef]

6. Tang, M.X.; Redemann, C.T.; Szoka, F.C., Jr. In vitro gene delivery by degraded polyamidoamine dendrimers. Bioconjug. Chem. 1996, 7, 703-714. [CrossRef]

7. Fox, L.J.; Richardson, R.M.; Briscoe, W.H. PAMAM dendrimer-cell membrane interactions. Adv. Colloid Interface Sci. 2018, 257, 1-18. [CrossRef]

8. Li, J.; Liang, H.; Liu, J.; Wang, Z. Poly (amidoamine) (PAMAM) dendrimer mediated delivery of drug and pDNA/siRNA for cancer therapy. Int. J. Pharm. 2018, 546, 215-225. [CrossRef]

9. Luong, D.; Kesharwani, P.; Deshmukh, R.; Mohd Amin, M.C.I.; Gupta, U.; Greish, K.; Iyer, A.K. PEGylated PAMAM dendrimers: Enhancing efficacy and mitigating toxicity for effective anticancer drug and gene delivery. Acta Biomater. 2016, 43, 14-29. [CrossRef]

10. Fang, R.H.; Hu, C.M.; Luk, B.T.; Gao, W.; Copp, J.A.; Tai, Y.; O'Connor, D.E.; Zhang, L. Cancer cell membrane-coated nanoparticles for anticancer vaccination and drug delivery. Nano Lett. 2014, 14, 2181-2188. [CrossRef]

11. Parodi, A.; Quattrocchi, N.; van de Ven, A.L.; Chiappini, C.; Evangelopoulos, M.; Martinez, J.O.; Brown, B.S.; Khaled, S.Z.; Yazdi, I.K.; Enzo, M.V.; et al. Synthetic nanoparticles functionalized with biomimetic leukocyte membranes possess cell-like functions. Nat. Nanotechnol. 2013, 8, 61-68. [CrossRef] [PubMed]

12. Hu, C.M.; Fang, R.H.; Copp, J.; Luk, B.T.; Zhang, L. A biomimetic nanosponge that absorbs pore-forming toxins. Nat. Nanotechnol. 2013, 8, 336-340. [CrossRef] [PubMed]

13. Hu, Q.; Sun, W.; Qian, C.; Wang, C.; Bomba, H.N.; Gu, Z. Anticancer Platelet-Mimicking Nanovehicles. Adv. Mater. 2015, 27, 7043-7050. [CrossRef] [PubMed]

14. Zhang, Y.; Chen, Y.; Lo, C.; Zhuang, J.; Angsantikul, P.; Zhang, Q.; Wei, X.; Zhou, Z.; Obonyo, M.; Fang, R.H.; et al. Inhibition of pathogen adhesion by bacterial outer membrane-coated nanoparticles. Angew. Chem. Int. Ed. (English) 2019, 58, 11404-11408. [CrossRef]

15. Chen, Y.; Zhang, Y.; Chen, M.; Zhuang, J.; Fang, R.H.; Gao, W.; Zhang, L. Biomimetic nanosponges suppress in vivo lethality induced by the whole secreted proteins of pathogenic bacteria. Small 2019, 15, e1804994. [CrossRef]

16. Molinaro, R.; Evangelopoulos, M.; Hoffman, J.R.; Corbo, C.; Taraballi, F.; Martinez, J.O.; Hartman, K.A.; Cosco, D.; Costa, G.; Romeo, I.; et al. Design and development of biomimetic nanovesicles using a microfluidic approach. Adv. Mater. 2018, 30, e1702749. [CrossRef]

17. Corbo, C.; Cromer, W.E.; Molinaro, R.; Toledano Furman, N.E.; Hartman, K.A.; De Rosa, E.; Boada, C.; Wang, X.; Zawieja, D.C.; Agostini, M.; et al. Engineered biomimetic nanovesicles show intrinsic anti-inflammatory properties for the treatment of inflammatory bowel diseases. Nanoscale 2017, 9, 14581-14591. [CrossRef]

18. Molinaro, R.; Pasto, A.; Corbo, C.; Taraballi, F.; Giordano, F.; Martinez, J.O.; Zhao, P.; Wang, X.; Zinger, A.; Boada, C.; et al. Macrophage-derived nanovesicles exert intrinsic anti-inflammatory properties and prolong survival in sepsis through a direct interaction with macrophages. Nanoscale 2019, 11, 13576-13586. [CrossRef]

19. Zhai, Y.; Su, J.; Ran, W.; Zhang, P.; Yin, Q.; Zhang, Z.; Yu, H.; Li, Y. Preparation and application of cell membrane-camouflaged nanoparticles for cancer therapy. Theranostics 2017, 7, 2575-2592. [CrossRef]

20. O'Sullivan, T.E.; Sun, J.C.; Lanier, L.L. Natural killer cell memory. Immunity 2015, 43, 634-645. [CrossRef]

21. Vivier, E.; Raulet, D.H.; Moretta, A.; Caligiuri, M.A.; Zitvogel, L.; Lanier, L.L.; Yokoyama, W.M.; Ugolini, S. Innate or adaptive immunity? The example of natural killer cells. Science 2011, 331, 44-49. [CrossRef] [PubMed]

22. Zhu, L.; Oh, J.M.; Gangadaran, P.; Kalimuthu, S.; Baek, S.H.; Jeong, S.Y.; Lee, S.-W.; Lee, J.; Ahn, B.-C. Targeting and therapy of glioblastoma in a mouse model using exosomes derived from natural killer cells. Front. Immunol. 2018, 9, 824. [CrossRef] [PubMed]

23. Lugini, L.; Cecchetti, S.; Huber, V.; Luciani, F.; Macchia, G.; Spadaro, F.; Paris, L.; Abalsamo, L.; Colone, M.; Molinari, A.; et al. Immune surveillance properties of human NK cell-derived exosomes. J. Immunol. 2012, 189, 2833-2842. [CrossRef] [PubMed]

24. Zhu, L.; Kalimuthu, S.; Gangadaran, P.; Oh, J.M.; Lee, H.W.; Baek, S.H.; Jeong, S.Y.; Lee, S.W.; Lee, J.; Ahn, B.C. Exosomes derived from natural killer cells exert therapeutic effect in melanoma. Theranostics 2017, 7, 2732-2745. [CrossRef] [PubMed]

25. Jong, A.Y.; Wu, C.H.; Li, J.; Sun, J.; Fabbri, M.; Wayne, A.S.; Seeger, R.C. Large-scale isolation and cytotoxicity of extracellular vesicles derived from activated human natural killer cells. J. Extracell. Vesicles 2017, 6, 1294368. [CrossRef] 
26. Parolini, I.; Federici, C.; Raggi, C.; Lugini, L.; Palleschi, S.; De Milito, A.; Coscia, C.; Iessi, E.; Logozzi, M.; Molinari, A.; et al. Microenvironmental $\mathrm{pH}$ is a key factor for exosome traffic in tumor cells. J. Biol. Chem. 2009, 284, 34211-34222. [CrossRef] [PubMed]

27. Oberschmidt, O.; Kloess, S.; Koehl, U. Redirected primary human chimeric antigen receptor natural killer cells as an "off-the-shelf immunotherapy" for improvement in cancer treatment. Front. Immunol. 2017, 8, 654. [CrossRef]

28. Fujisaki, H.; Kakuda, H.; Shimasaki, N.; Imai, C.; Ma, J.; Lockey, T.; Eldridge, P.; Leung, W.H.; Campana, D. Expansion of highly cytotoxic human natural killer cells for cancer cell therapy. Cancer Res. 2009, 69, 4010-4017. [CrossRef]

29. Théry, C.; Amigorena, S.; Raposo, G.; Clayton, A. Isolation and characterization of exosomes from cell culture supernatants and biological fluids. Curr. Protoc. Cell Biol. 2006, 30, 3-22. [CrossRef]

30. Lotvall, J.; Hill, A.F.; Hochberg, F.; Buzas, E.I.; Di Vizio, D.; Gardiner, C.; Gho, Y.S.; Kurochkin, I.V.; Mathivanan, S.; Quesenberry, P.; et al. Minimal experimental requirements for definition of extracellular vesicles and their functions: A position statement from the International Society for Extracellular Vesicles. J. Extracell. Vesicles 2014, 3, 26913. [CrossRef]

31. Fonseca, A.C.; Frias, M.A.; Bouchet, A.M.; Jarmelo, S.; Simoes, P.N.; Fausto, R.; Gil, M.H.; Lairion, F.; Disalvo, E.A. Role of guanidyl moiety in the insertion of arginine and Nalpha-benzoyl-L-argininate ethyl ester chloride in lipid membranes. J. Phys. Chem. B 2010, 114, 5946-5952. [CrossRef] [PubMed]

32. Zeng, H.; Little, H.C.; Tiambeng, T.N.; Williams, G.A.; Guan, Z. Multifunctional dendronized peptide polymer platform for safe and effective siRNA delivery. J. Am. Chem. Soc. 2013, 135, 4962-4965. [CrossRef] [PubMed]

33. Wang, F.; Wang, Y.; Wang, H.; Shao, N.; Chen, Y.; Cheng, Y. Synergistic effect of amino acids modified on dendrimer surface in gene delivery. Biomaterials 2014, 35, 9187-9198. [CrossRef] [PubMed]

34. Powers, J.T.; Tsanov, K.M.; Pearson, D.S.; Roels, F.; Spina, C.S.; Ebright, R.; Seligson, M.; de Soysa, Y.; Cahan, P.; Theissen, J.; et al. Multiple mechanisms disrupt the let-7 microRNA family in neuroblastoma. Nature 2016, 535, 246-251. [CrossRef]

35. Molenaar, J.J.; Domingo-Fernandez, R.; Ebus, M.E.; Lindner, S.; Koster, J.; Drabek, K.; Mestdagh, P.; van Sluis, P.; Valentijn, L.J.; van Nes, J.; et al. LIN28B induces neuroblastoma and enhances MYCN levels via let-7 suppression. Nat. Genet. 2012, 44, 1199-1206. [CrossRef]

36. Li, Y.M.; Pan, Y.; Wei, Y.; Cheng, X.; Zhou, B.P.; Tan, M.; Zhou, X.; Xia, W.; Hortobagyi, G.N.; Yu, D.; et al. Upregulation of CXCR4 is essential for HER2-mediated tumor metastasis. Cancer Cell 2004, 6, 459-469. [CrossRef]

37. Bajetto, A.; Barbieri, F.; Dorcaratto, A.; Barbero, S.; Daga, A.; Porcile, C.; Ravetti, J.L.; Zona, G.; Spaziante, R.; Corte, G.; et al. Expression of CXC chemokine receptors 1-5 and their ligands in human glioma tissues: Role of CXCR4 and SDF1 in glioma cell proliferation and migration. Neurochem. Int. 2006, 49, 423-432. [CrossRef]

38. Jaiswal, S.; Jamieson, C.H.; Pang, W.W.; Park, C.Y.; Chao, M.P.; Majeti, R.; Traver, D.; van Rooijen, N.; Weissman, I.L. CD47 is upregulated on circulating hematopoietic stem cells and leukemia cells to avoid phagocytosis. Cell 2009, 138, 271-285. [CrossRef]

39. Fais, S.; Logozzi, M.; Lugini, L.; Federici, C.; Azzarito, T.; Zarovni, N.; Chiesi, A. Exosomes: The ideal nanovectors for biodelivery. Biol. Chem. 2013, 394, 1-15. [CrossRef]

40. Hernandez, P.A.; Gorlin, R.J.; Lukens, J.N.; Taniuchi, S.; Bohinjec, J.; Francois, F.; Klotman, M.E.; Diaz, G.A. Mutations in the chemokine receptor gene CXCR4 are associated with WHIM syndrome, a combined immunodeficiency disease. Nat. Genet. 2003, 34, 70-74. [CrossRef]

41. Liotta, L.A. An attractive force in metastasis. Nature 2001, 410, 24-25. [CrossRef] [PubMed]

42. Muller, A.; Homey, B.; Soto, H.; Ge, N.; Catron, D.; Buchanan, M.E.; McClanahan, T.; Murphy, E.; Yuan, W.; Wagner, S.N.; et al. Involvement of chemokine receptors in breast cancer metastasis. Nature 2001, 410, 50-56. [CrossRef] [PubMed]

(C) 2019 by the authors. Licensee MDPI, Basel, Switzerland. This article is an open access article distributed under the terms and conditions of the Creative Commons Attribution (CC BY) license (http://creativecommons.org/licenses/by/4.0/). 